\title{
Interaksi Antara Zat Aktif dan Eksipien dalam Sediaan Farmasi
}

\author{
Faizal Alfaridz $z^{*}$, , Ida Musfiroh ${ }^{2}$ \\ ${ }^{1}$ Program Studi Profesi Apoteker, Fakultas Farmasi, Universitas Padjadjaran, Jatinangor 45363 \\ ${ }^{2}$ Departemen Analisis Farmasi dan Kimia Medisinal, Fakultas Farmasi, Universitas Padjadjaran, Jatinangor 45363 \\ *email: faizal15003@unpad.mail.ac.id \\ (Submit 19/1/2020, Revisi 28/1/2020, Diterima 29/1/2020)
}

\begin{abstract}
Abstrak
Perkembangan formula pada sediaan farmasi semakin pesat terbukti dengan adanya bentuk sediaan baru serta campuran eksipien pendukung yang rumit. Pengembangan suatu formula tidaklah mudah karena perlu bertahun-tahun agar mendapatkan hasil yang optimal. Salah satu permasalahan dalam pengembangan formula adalah interaksi yang terjadi pada formula tersebut, terutama pada zat aktif dengan eksipien maupun degradannya. Interaksi yang terjadi dapat berupa interaksi fisika seperti pembentukan kompleks, adsorpsi dan dispersi solida ; sedangkan untuk interaksi kimia seperti reaksi Maillard, dan transesterifikasi. Pada studi pustaka ini akan dibahas bagaimana interaksi tersebut terjadi antara zat aktif-eksipien pada sediaan farmasi.
\end{abstract}

Kata Kunci : Degradan, Interaksi Fisika, Interaksi Kimia.

\section{Outline}

- Pendahuluan

- Hasil \& Pembahasan

- Dekomposisi Obat

- Mekanisme Interaksi Zat Aktif dengan Eksipien

- Interaksi Fisika

- Interaksi Kimia

- Perspektif Penulis

- Kesimpulan

- Daftar Pustaka

\section{Pendahuluan}

Obat adalah suatu bahan atau campuran bahan aktif yang digunakan dalam mendiagnosis, mengobati, mengurangi, dan menghilangkan suatu penyakit (DEPKES $\mathrm{RI}, 2018$ ). Perkembangan obat sekarang ini sangat pesat terbukti dengan banyaknya bentuk sediaan yang beredar di dunia seperti sirup, suspensi, tablet, emulsi, suspensi, injeksi dll yang masing-masing memiliki kelebihan. Perkembangan obat juga tidak hanya didukung dengan penemuan bentuk sediaan baru tapi juga dengan adanya eksipien-eksipien pendukung yang baru serta campurannya yang semakin rumit untuk mendapatkan formula yang baik (Allen, 2008). 
Pengembangan suatu formula untuk mendapatkan formula yang baik dan aman tidaklah mudah dan perlu waktu bertahun-tahun untuk mengoptimasi formula tersebut (Horien and Yuan, 2017). Salah satu yang membuat pengembangan suatu formula sulit adalah interaksi dalam formula tersebut. Interaksi yang biasa terjadi adalah antara bahan aktif dengan eksipiennya, bahan aktif dengan bahan aktif atau eksipien dengan eksipiennya. Untuk itu kita perlu mengetahui sifat fisikokimia suatu bahan agar hal tersebut dapat dicegah dan tidak terjadi (Chadha and Bhandari, 2014).

Bahan tambahan atau eksipien pada dasarnya inert atau tidak menyebabkan interaksi, namun eksipien dapat menginisiasi, mempropagasi dan berpartisipasi dalam terjadinya interaksi baik secara kimia maupun fisika (Patel et al., 2015). Interaksi tersebut dapat terjadi karena ada gugus fungsional yang berinteraksi secara langsung dengan zat aktif. Selain itu, bahan pengotor atau residu, dan bahkan eksipien tersebut menghasilkan produk degradan yang dapat menyebabkan terjadinya interaksi. Oleh karenanya penting bagi suatu formulator memahami tiga aspek penting dalam formulasi yaitu :

- Sifat fisikokimia zat aktif

- Sifat fisikokimia eksipien

- Kelebihan dan kekurangan metode pembuatan bentuk sediaan.

(Fathima et al., 2011)

Review ini membahas tentang macam degradasi yang mungkin terjadi pada suatu bahan serta interaksi kimia dan fisika dan dapat terjadi di dalam suatu sediaan.

\section{Metode}

Pencarian data dalam review jurnal ini diambil berdasarkan referensi jurnal ilmiah yang berkaitan dengan interaksi dalam formulasi. Adapun kriteria yang digunakan yaitu jurnal ilmiah yang dimaksudkan berupa naskah publikasi nasional dan internasional tahun 2002-2017 dengan tema berfokus kepada interaksi fisika dan kimia yang terjadi dalam suatu formulasi. Jumlah studi yang digunakan dalam review jurnal ini sebanyak 20 jurnal.

\section{Hasil dan Pembahasan}

\section{Dekomposisi Obat}

Suatu bahan obat memiliki gugus fungsional yang berinteraksi dengan reseptor untuk menghasilkan efek terapi. Namun disisi lain gugus fungsional ini juga dapat berinteraksi dengan komponen senyawa lain dalam gabungan suatu formula seperti hidrolisis, isomerasi, oksidasi, dan fotolisis (Kumar et al., 2011). Interaksi tersebut akan menghasilkan dekomposisi dari ekspien dan masing-masing dari dekomposisi tersebut akan diuraikan dibawah :

\section{Oksidasi}

Merupakan proses degradasi obat yang berhubungan dengan mekanisme transfer elektron dimana akan membentuk anion dan kation yang reaktif. Gugus - gugus seperti sulfida, amina dan fenol rentan mengalami transfer elektron oksidasi yang akan menjadi sulfones, sulfoxide, $\mathrm{N}$-oxides dan hydroxylamine (Blessy et al., 2014). 
Reaksi oksidasi juga dapat dipercepat dengan adanya ion logam berat, oksigen dan cahaya yang menyebabkan terbentuknya radikal bebas. Radikan bebas ini akan berinteraksi dengan oksigen dan membentuk peroksi radikal yang sangat reaktif dan menyebabkan oksidasi (Patel et al., 2015).

\section{Isomerisasi}

Stereoisomer merupakan molekul yang identik secara konstitusi atom dan ikatan, namun berbeda pada konformasi tiga dimensinya (3D). Salah satu contoh peristiwanya adalah enantiomer yang merupakan bayangan kaca dari molekul yang identik namun sifatnya dapat berbeda jauh (seperti Levo dan Dextro) (Chhabra et al., 2013).

Isomer dari suatu zat memilki sifat fisikokimia yang identik seperti pKa, kelarutan, titik leleh, titik didih dll. Perbedaan yang mencolok dari isomer adalah rotasi dari zat tersebut akan berlawanan seperti cermin. Contohnya yaitu perbedaan farmakokinetik pada LMetotreksat lebih baik dalam hal absorpsi dibandingkan D-Metotreksat, dan S-Warfarin lebih mudah terikat pada albumin dibandingkan R-Warfarin (Brunton et al., 2011).

\section{Hidrolisis}

Hidrolisis merupakan proses pemecahan struktur kimia akibat adanya air. Hidrolisis ini cukup sering terjadi pada zat aktif maupun eksipien karena ketidakstabilan zat tersebut pada saaat terkena air (Waterman et al., 2002). Obat-obat yang memiliki gugus fungsi seperti ester, amida, lakton rentan mengalami degradasi akibat hidrolisis. Hidrolisis sering terjadi pada sediaan farmasi karena banyak zat aktif yang memilik gugus fungsi tersebut dan tidak kuat terhadap air (Patel et al., 2015).

\section{Fotolisis}

Fotostabilitas merupakan respon yang ditimbulkan dari suatu zat saat dikenai paparan sinar UV atau cahaya tampak pada waktu tertentu yang berujung pada perubahan secara kimia maupun fisika (Ahmad et al., 2016). Energi foton (cahaya) akan semakin besar pada panjang gelombang yang kecil dan sebaliknya. Degradasi umumnya terjadi akibat terpapar energi yang besar dengan panjang gelombang kecil (radiasi) yang menyebabkan perubahan kimia (warna) (Fathima et al., 2011).

Contoh obat-obatan yang rentan mengalami degradasi akibat peristiwa diatas dapat dilihat pada tabel berikut :

Tabel 1. Obat-obatan yang mengalami peristiwa degradasi (Patel et al., 2015).

\begin{tabular}{|llll|}
\hline Hidrolisis & Oksidasi & Isomerisasi & Fotolisis \\
\hline Metildopa & Kalsitonin & Tetrasiklin & Riboflavin \\
\hline Penisilin & Isoprenalin & Vitamin A & Nifedipin \\
\hline Procaine & Vitamin C & Adrenaline & Asam folat \\
\hline
\end{tabular}




\section{Mekanisme Interaksi Zat Aktif dengan Eksipien}

Interaksi dapat terjadi pada sediaan farmasi terutama yang memiliki formula yang kompleks. Umumnya interaksi pada sediaan farmasi dapat dibagi menjadi dua yaitu interaksi fisika dan interaksi kimia (Fathima et al., 2011).

\section{Interaksi Fisika}

Interaksi fisika merupakan interaksi yang cukup umum terjadi pada sediaan farmasi, interaksi fisika dapat mempengeruhi interaksi kimia. Interaksi yang umum terjadi biasanya melibatkan perubahan laju disolusi atau perubahan wanra (Fathima et al., 2011). Contoh interaksi fisika adalah pembentukan kompleks, adsorpsi dan dispersi solida (Patel et al., 2015).

\section{Pembentukan Kompleks}

Reaksi ini terjadi antara agen pembuat kompleks dengan zat aktif. Biasanya ikatan yang terjadi dapat bersifat reversibel maupun ireversibel. Dampak yang ditimbulkan dari pembentukan kompleks ini adalah penurunan laju disolusi dan pengurangan absorpsi obat. Contoh dari peristiwa tersebut adalah kalsium karbonat yang dapat membentuk kompleks dengan tetrasiklin yang menyebabkan penurunan laju disolusi dan pengurangan absorpsi obat dan gugus fungsi fenol yang dapat membentuk kompleks dengan logam-logam berat dan menyebabkan pembentukan kompleks tidak larut. Reaksi pembentukan kompleks disini tidak selalu berdampak negatif, namun juga dapat berdampak positif karena dapat dimanfaatkan untuk meningkatkan bioavailabilitas pada obat-obat yang kurang larut dalam air seperti eksipien siklodekstrin yang dapat meningkatkan bioavailabilitas pada obat-obat yang kurang larut dalam air (Bharate et al., 2010; Patel et al., 2015).

\section{Adsorpsi}

Merupakan peristiwa penempelan satu zat pada zat lain dimana dapat berdampak negatif maupun positif. Untuk negatif dapat menyebabkan penurunan bioavailabilitas karena zat aktif menempel pada zat eksipien dan tidak terdisolusi, sedangkan untuk hal positif adsorpsi dapat dimanfaatkan untuk meningkatkan luas permukaan dari zat aktif untuk lebih mudah terdisolusi dan meningkatkan bioavailabilitas. Contoh dari adsorpsi adalah obat NSAID (Aspirin, Indometasin, dan Ibuprofen) dapat ditingkatkan laju disolusinya dengan menggunakan kaolin sebagai adsorben dan meningkatkan bioavailabilitas obat (Fathima et al., 2011; Patel et al., 2015).

\section{Dispersi Solida}

Interaksi ini sering dimanfaatkan untuk meningkatkan bioavailabilitas dari obat-obat yang bersifat hidrofobik, tapi tidak jarang juga interaksi ini dapat menurunkan disolusi dari obat. Contohnya adalah Iburofen, Nifedipin, dan Piroksikam yang meningkat laju disolusinya saat diformulasikan dispersi padat dengan polietilene glikol. Sedangkan untuk Povidon saat berinteraksi dengan asam strearat pada kapsul justru menurunkan laju disolusinya (Patel et al., 2015). 
Interaksi Kimia

Interaksi yang melibatkan serangkaian reaksi kimia antara zat aktif dengan eksipien atau zat aktif dengan residu yang ditimbulkan dari ekspien tersebut. Reaksi kimia umumnya bersifat merugikan karena dapat menghasilkan produk degradan yang tidak diinginkan (Hotha et al., 2016). Adapun degradan yang mungkin terbentuk dari beberapa eksipien yaitu :

Tabel 2. Eksipien dan Degradannya (Baertschi et al., 2011)

\begin{tabular}{|cc|}
\hline $\begin{array}{c}\text { Eksipien } \\
\text { crospovidon, }\end{array}$ & $\begin{array}{c}\text { Degradan } \\
\text { Peroksida }\end{array}$ \\
\hline Lactose & $\begin{array}{c}\text { Aldehid, gula } \\
\text { pereduksi }\end{array}$ \\
\hline Talkum & Logam berat \\
\hline Kanji (Starch) & Formaldehid \\
\hline $\begin{array}{c}\text { Hydroxy propil } \\
\text { metil/etil selulosa }\end{array}$ & Glyoxal \\
\hline Benzil alkohol & Benzaldehid \\
\hline Mikrokristalin & Lignin, hemiselulosa \\
selulosa & \\
\hline
\end{tabular}

Interaksi kimia yang terjadi antara degradan dari eksipien dengan zat aktif pada obat dapat disebabkan karena degradan tersebut memiliki gugus-gugus fungsi tertentu dan menyebabkan beberapa proses seperti :

\section{Aldehid}

Umumnya eksipien-eksipien pada sediaan farmasi mengandung residu aldehid. Residu ini terbentuk akibat degradasi dari eksipien, terutama karena adanya oksidasi. Walaupun dalam bentuk residu, aldehihd dapat mempengaruhi stabilitas dan efikasi dari zat aktif dengan berinteraksi secara langsung. Contoh dari peristiwa tersebut adalah Famotidine yang berinteraksi dengan perasa ceri, dimana perasa ceri tersebut memiliki aldehid dan keton sebagai pembentuk rasa tersebut. Walaupun dengan jumlah yang kecil, interaksi dapat terjadi antara famotidine dengan benzaldehid yang merupakan residu dari perasa ceri.

Interaksi tersebut menghasilkan zat yang belum diketahui dengan instrumen Ultra Performance Liquid Chromatography (UPLC). Interaksi tersebut terjadi karena zat aktif Famotidine memiliki gugus amin yang dapat berinteraksi dengan benzaldehid (Hotha et al., 2015). Adapun kromatogram dari interaksi antara Famotidine dan Benzaldehid dapat dilihat pada gambar 1 . 


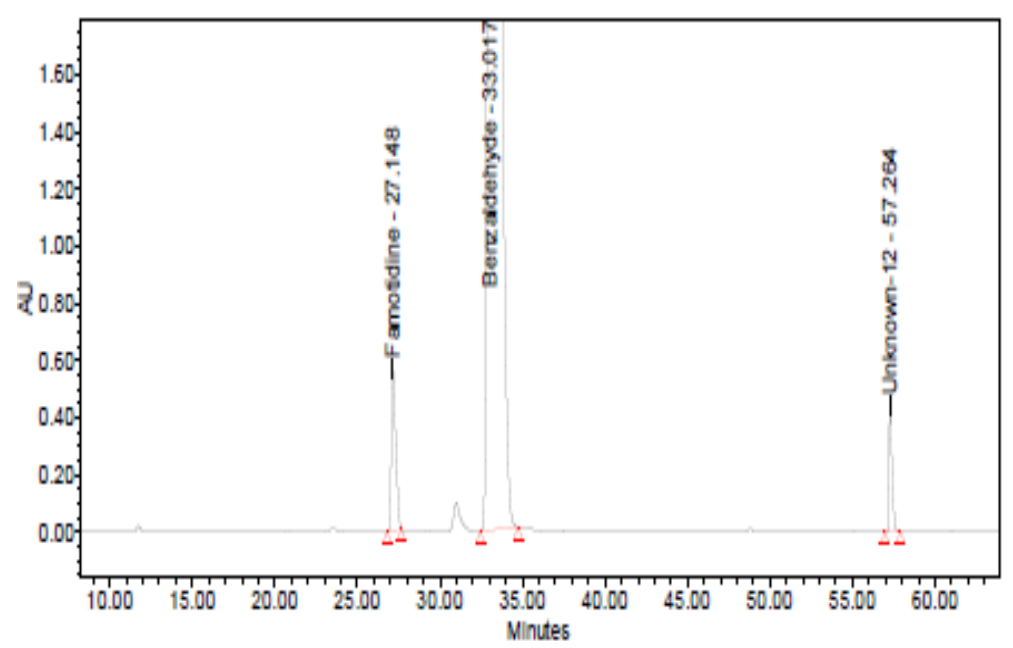

Gambar 1. Interaksi Famotidine dengan Benzaldehid pada Perasa Ceri pada UPLC (Hotha et al., 2015).

\section{Transesterifikasi}

Transesterifikasi merupakan proses perubahan gugus fungsi pada gugus ester zat organik menjadi gugus alkohol. Reaksi ini dapat terjadi akibat adanya katalis seperti asam dan basa kuat yang dimana pada suasana asam akan mendonasikan proton pada gugus karbonil (lebih elektrofilik) sedangkan pada basa kuat akan menghilangkan proton pada gugus karbonil (lebih nukleofilik) (Meireles and Pereira, 2013).Contoh dari peristiwa transesterifikasi adalah reaksi antara sorbitol dengan paraben. Kedua zat ini sering digunakan pada sediaan farmasi terutama sediaan oral.

Transerterifikasi dapat terjadi karena adanya perubahan gugus ester pada metil paraben yang dirubah menjadi gugus alkohol oleh penempelan sorbitol. Hal tersebut diteliti oleh $\mathrm{Ma}$ et al dimana formula yang mengandung sorbitol dan metil paraben menghasilkan degradan sebanyak $1 \%$ pada penyimpanan selama 1 tahun pada suhu $30^{\circ} \mathrm{C}$ (Ma et al., 2002). Gambar 2 merupakan reaksi antara sorbitol dengan metil paraben.
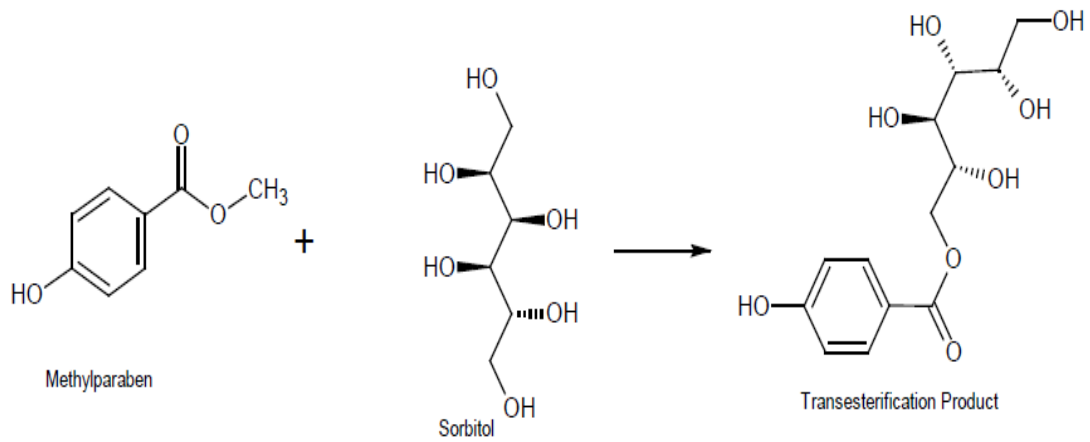

Gambar 2. Transesterifikasi antara Metilparaben dan Sorbitol (Ma et al., 2002) 
Maillard

Reaksi Maillard pertama kali ditemukan oleh Louis Maillard pada tahun 80an dimana terjadi reaksi perubahan warna menjadi coklat antara gugus aldehid dengan gugus amin saat dipanaskan (Kumar and Banker, 2005). Gugus aldehid banyak terdapat pada gula terutama gula pereduksi yang dapat berinteraksi dengan zat aktif dan membentuk Glycosylamine (Hotha et al., 2016). Contoh peristiwa Maillard adalah dextrosa dengan zat aktif Setralin yang merupakan obat antidepresan golongan inhibitor selektif reuptake serotonin. Hal tersebut dapat terjadi karena dextrosa sebagai gula pereduksi dapat berinteraksi dengan gugus amin yang terdapat pada setralin yang menyebabkan pembentukan glycosylamine pada penataulangan Amadori (Ghaderi et al., 2017).

\section{Magnesium Stearat}

Magnesium stearat merupakan komponen yang sering dipakai pada tablet sebagai lubrikan untuk mencegah penempelan pada die tablet. Kehadiran magnesium stearat pada formula tablet kadang dapat menyebabkan timbulnya degradan. Contohnya adalah pada tablet yang mengandung zat aktif Tacrolimus dan eksipien magnesium stearat. Reaksi antara tacrolimus dengan magnesium stearat menghasilkan asam alfahidroksi dimana reaksi tersebut terjadi akibat adanya logam kation bivalen (+2) pada pH yang tinggi (Rozman et al., 2015).

\section{Perspektif Penulis}

Pemikiran penulis dalam review artikel ini didasarkan kepada tahapan utama dalam formulasi yaitu memperhatikan sifat fisikokimia zat utama (zat aktif) untuk menyeleksi zat tambahan yang akan menunjang terhadap kestabilan zat utama. Selain itu beberapa interaksi seperti interaksi fisika dan kimia yang dibahas merupakan interaksi yang umum terjadi pada kebanyakan sediaan (liquid, semisolid dan solida).

\section{Kesimpulan}

Berdasarkan pokok bahasan yang telah dibahas interaksi antar zat dapat terjadi dalam suatu formula. Baik antara zat aktif dengan eksipien, ataupun degradan dari eksipien dengan zat aktif. Interaksi tersebut dapat terjadi secara fisika maupun kimia yang dapat menguntungkan maupun merugikan.

Struktur dari zat aktif dan eksipien sebaiknya menjadi pertimbangan dalam formulasi untuk mencegah terjadinya interaksi yang merugikan. Diharapkan artikel ini dapat memberi gambaran interaksi yang mungkin terjadi dalam suatu formula agar tidak terjadi permasalahan saat melakukan formulasi sediaan. 


\section{Daftar Pustaka}

Ahmad, I., Ahmed, S., Anwar, Z., Sheraz, M.A., Sikorski, M., 2016. Photostability and Photostabilization of Drugs and Drug Products. Int. J. Photoenergy 1, 1-19.

Allen, L.V., 2008. Dosage Form Design and Development. Clin. Ther. 30, 2102-2111. Baertschi, S.W., Alsante, K.M., Reed, R.A., 2011. Pharmaceutical Stress Testing: Predicting Drug Degradation, 2nd ed. Informa Health Care.

Bharate, S.S., Bharate, S.B., Bajaj, A.N., 2010. Interactions and incompatibilities of pharmaceutical excipients with active pharmaceutical ingredients: a comprehensive review. J. Excip. Food Chem. 1, 3-26.

Blessy, M., Ruchi, D.P., Prajesh N, P., Agrawal, Y.K., 2014. Development of forced degradation and stability indicating studies of drugs - A review. J. Pharm. Anal. 4, 159165.

Brunton, L., Parker, K., Blumenthal, D., Buxton, I., 2011. Goodman and Gilman's Manual of Pharmacology and Therapeutics, 12th ed. Mc Graw Hill Company, New York.

Chadha, R., Bhandari, S., 2014. Drug-excipient compatibility screening-Role of thermo analytical and spectroscopic techniques. J. Pharm. Biomed. Anal. 87, 82-97.

Chhabra, N., Aseri, M.L., Padmanabhan, D., 2013. A review of drug isomerism and its significance. Int. J. Appl. Basic Med. Res. 3, 16-18.

DEPKES RI, 2018. Cara Pembuatan Obat yang Baik. Departemen Kesehatan Republik Indonesia, Jakarta.

Fathima, N., Tirunagari, M., Qureshi, H.K., Anitha, N., Rao, J.V., 2011. Drug-excipient interaction and its importance in dosage form development. J. Appl. Pharm. Sci. 01, 6671.

Ghaderi, F., Nemari, M., Siahi-Shadbad, M.R., Valizadeh, H., Monajjemzadeh, F., 2017. Tracking of the Maillard reaction products in Pharmaceutical formulation of sertraline hydrochloride. Int. J. Res. Appl. Basic Med. Sci. 3, 1-10.

Horien, C., Yuan, P., 2017. Drug Development. YALE J. Biol. Med. 90, 1-3.

Hotha, K.K., Patel, T., Roychowdhury, S., Subramanian, V., 2015. Identification, Synthesis, and Characterization of Unknown Imputiry in the Famotidine Powder for Oral Suspension Due to Excipient Interaction by UPLC-MS/MS and NMR. J. Liq. Chromatogr. Relat. Technol. 38, 977-985.

Hotha, K.K., Roychowdhury, S., Subramanian, V., 2016. Drug-Excipient Interactions: Case Studies and Overview of Drug Degradation Pathways. Am. J. Anal. Chem. 7, 107140. 
Kumar, B., Sahu, R., Rammamutrhy, K., Rao, S., Ramu, B., 2011. A review on mechanism, importance and methods of compatibility testing in the formulation of dosage forms. J. Chem. Pharm. Sci. 4, 141-151.

Kumar, V., Banker, G.S., 2005. Maillard Reaction and Drug Stability. Woodhead Publ. Ser. Food Sci. Technol. Nutr. 20-27.

Ma, M., DiLollo, A., Mercuri, R., Lee, T., Bundang, M., Kwong, E., 2002. HPLC and LCMS Studies of the Transesterification Reaction of Methylparaben with Twelve 3- to 6carbon Sugar Alcohols and Propylene Glycol and the Isomerization of the Reaction Products by Acyl Migration. J. Chromatogr. Sci. 40, 170-177.

Meireles, B.A., Pereira, V.L.P., 2013. Synthesis of Bio-Additives: Transesterification of Ethyl Acetate with Glycerol Using Homogeneous or Heterogeneous Acid Catalysts. J. Braz. Chem. Soc. 24, 17-25.

Patel, P., Ahir, K., Patel, V., Manani, L., Patel, C., 2015. Drug-Excipient compatibility studies: First step for dosage form development. Pharma Innov. J. 4, 14-20.

Rozman, P.T., Grahek, R., Hren, J., Bastarda, A., Bergles, J., Urleb, U., 2015. Solid State Compatibility Study and Characerication of a Novel Degradation Product of Tacrolimus in Formulation. J. Pharm. Biomed. Anal. 110, 67-75.

Waterman, K.C., Adami, R.C., Rebecca, C., Hong, J., Landis, M.S., Lombardo, F., Shah, J.C., Shalaev, E., Smith, S.W., Wang, H., 2002. Hydrolysis in Pharmaceutical Formulations. Pharm. Dev. Technol. 7, 113-146. 